\title{
Primary Fixation of Intertrochanteric Fracture with Hemiarthroplasty in Elderly Patients
}

\section{Ibrahim Mostafa, Hesham Safwat, Ahmed Saeed Abdel Raouf Sadeek*}

Department of Orthopedic Surgery, Faculty of Medicine, Al-Azhar University, Cairo, Egypt

*Corresponding author: Ahmed Saeed Abdel Raouf Sadeek, Mobile: (+20)01098066015, E-Mail:drraouf2011@gmail.com

\begin{abstract}
Background: trochanteric fractures are extracapsular fractures of the proximal femur between the greater and lesser trochanters. Approximately half of all hip fractures will be trochanteric fractures. Trochanteric fractures occur in a more aged population than do femoral neck fractures. These elderly people are more affected by osteoporosis and medical comorbidities.
\end{abstract}

Objective: the aim of this study was to evaluate the results of primary hemiarthroplasty in management of intertrochanteric fractures in elderly patients.

Patients and Methods: this study was a prospective study involving 20 patients with unstable trochanteric fractures performed at Orthopedic Department, Al Hussein and Sayed Galal, Al-Azhar University Hospitals between the period of September 2017 till March 2019. Patients were checked with X-rays, clinical evaluation, and functional assessment according to the Harris hip score (HHS).

Results: in the current study, data on the effect of internal fixation versus endoprosthesis on mortality rate are available only for femoral neck fractures. When adjusted for age, there is no significant difference in the mortality rates for patients treated with internal fixation or hemiarthroplasty.

Conclusion: It could be concluded that the use of hemiarthroplasty is recommended for cases with old age, osteoporotic bone, medical comorbidities, preexisting ipsilateral symptomatic degenerative hip disease or patients with renal failure or pathological fracture with metastases.

Keywords: Hip, Intertrochanteric fracture, Hemiarthropalsty, Elderly patient

\section{INTRODUCTION}

Hip fractures represent a major cause of disability and mortality in the elderly. The incidence of all hip fractures is approximately 80 per 100,000 persons and is expected to double over the next 50 years as the population ages, generating a major financial burden ${ }^{(\mathbf{1})}$.

Intertrochanteric and femoral neck fractures account for over $90 \%$ of hip fractures, occurring in approximately equal proportions ${ }^{(2)}$. Intertrochanteric fractures usually occur in a more elderly group than femoral neck fractures who are more susceptible to many complications as pneumonia, deep veins thrombosis, pulmonary embolism, bed sores and psychic depression. Also, these patients usually have associated systemic diseases of the cardiovascular system, pulmonary tree, genitourinary tract, osteoporosis and metabolic aberrations combining to the poor anesthetic and operative risks ${ }^{(3)}$.

Intertrochanteric fractures are extracapsular fractures of the proximal femur extending between the greater and lesser trochanters. In general, fractures with comminution of posteromedial cortex, subtrochanteric extension or reversed obliquity are considered unstable (4).

These fractures are seen in two populations, elderly patients after a low-energy fall and younger patients after high energy trauma as fall from high. Also, elderly patients are susceptible to metastatic bone diseases that lead to pathologic fractures ${ }^{(5)}$.

The management of these fractures evolved from conservative approach, with the help of skeletal traction to operative procedures such as fixed angle blade plates, sliding hip screw and lately the intramedullary devices. In fractures with stable configurations the results of osteosynthesis are better as compared with fractures with unstable configurations. These implants have their success when bone quality is good, but in elderly individuals with osteoporotic bone and unstable fracture patterns the complication rate is high such as screw cut out from head, excessive collapse of fragments leading to shortening, varus, rotational deformities and implant breakage. Though considerably less with intramedullary implants but screw cut out and implant breakage still remain ${ }^{(6)}$.

Prosthetic replacement of the femoral head appears to be a better alternative in unstable intertrochanteric fractures as it would provide rapid and early mobilization and return of function which is necessary in elderly individuals to reduce morbidity and mortality. The increased blood loss, mechanical complications like dislocation and the need for calcar replacement are possible complications for arthroplasty (7).

The aim of this study was to evaluate the results of primary hemiarthroplasty in management of intertrochantric fractures in elderly patients.

\section{PATIENTS AND METHODS}

This prospective study included a total of 20 patients with unstable trochanteric fractures attending at Orthopedic Department, Al Hussein and Sayed Galal, Al-Azhar University Hospitals. Approval of the ethical committee and a written informed consent 
from all the subjects were obtained. This study was conducted between September 2017 and March 2019.

Patients were checked with X-rays, clinical evaluation, and functional assessment according to the Harris hip score (HHS). According to the treatment, 20 patients were treated by hemiarthroplasty. These 20 patients were prospectively followed up for 3-11 months with average of 7 months.

\section{Inclusion criteria:}

- Unstable trochanteric fractures characterized by;

1. Posteromedial comminution or loss of femoral calcar.

2. Lateral wall comminution.

- Elderly people above the age of 70 both males and females. Primary hemiarthroplasty including Thompson and Bipolar.

\section{Exclusion criteria:}

- Other proximal femoral fractures including; fractures of neck of femur and subtrochanteric fractures.

- Fractures in non-elderly below the age of 60 .

- Revision and secondary hemiarthroplasty after osteosynthesis.

- External fixation methods are also excluded.

After approval by hospital ethics committee, an informed consent was taken from all the patients, preoperative preparation, operative technique, postoperative management and results were all assessed.

\section{Preoperative preparation:}

History was taken from these patients including the cause of the fall, any history of serious cardiac or neurological problems, and if any patient was on anticoagulation regimen. Also, assessment of nutritional status, osteoporosis, hypertension, diabetes, the pre trauma level of activity and the functional needs of the patient was done preoperatively. Assessment of the neurovascular status of the limb is also mandatory in these patients. Plain $x$ rays were obtained including anteroposterior (AP) pelvis, cross table lateral views and traction views with internal rotation of the affected hip. In some cases with subtrochanteric extension, a full length femoral AP and lateral radiographs to the knee were done to determine the femoral bow and medullary canal diameter. Patients were put in skin traction until time of surgery.

\section{Timing of the surgery:}

The timing of the surgery varied depending on the patient tolerability for operative intervention and availability of image intensifier.

\section{Operative technique:}

\section{Anesthesia:}

The surgery was done to all patients under spinal anesthesia.

\section{Preparation and patient positioning:}

Intravenous second or third generation cephalosporin antibiotics was administered 30 minutes prior to surgery to reduce the infection rate and continued for 25 days postoperatively.

For hemiarthroplasty, the operation was performed in lateral position on a radiolucent fracture table.

\section{Approach and technique of hemiarthroplasty:}

A Watson-Jones (anterolateral) surgical approach was performed. A lateral incision was made in line with the femur, extending up to the iliac crest and angulated in a posterior direction to finish 8 to $10 \mathrm{~cm}$ anterior to the posterior superior iliac spine. The fascia was then divided and a plane developed between the anterior edge of the gluteal muscles and tensor fascia lata to gain access to the capsule. The vastus lateralis was then released proximally from its origin leaving a cuff of tissue proximally for reattachment after fracture fixation. For better visualization of the anterior capsule, a blunt Hohman retractor was placed anteriorly and levered against the medial proximal femoral neck. The anteromedial wall and fracture site were then exposed .Fractured femoral head with neck was extracted by flexion \& external rotation at hip joint, preserving the greater \& lesser trochanter attached to the soft tissues by corkscrew. Head size measured. We prepared femoral medullary canal by sequential broaches in flexed \& externally rotated hip. Trial implants were placed \& hip was reduced to decide the final implants sizes. After removing the trial implants thorough wash given. Bone plug was placed in the medullary canal 2 centimeters below the tip of femoral stem. Canal was dried. Cementing was done with cement gun. Placement of femoral stem was done. Hip joint was reduced. Hemostasis was then confirmed, drain inserted and the wound closed in layer.
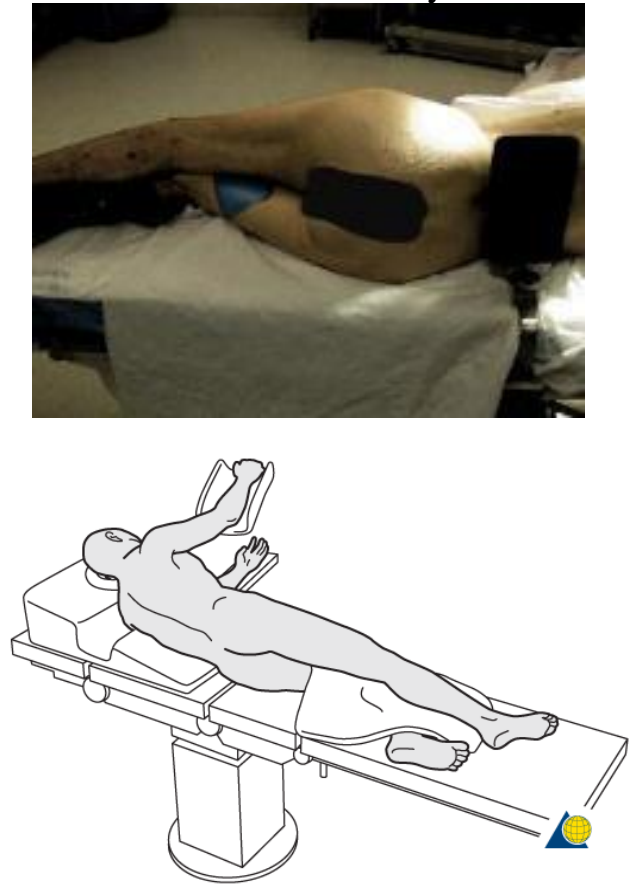

Figure (1): Lateral position. 


\section{Postoperative care and assessment:}

Anteroposterior radiographs on the entire fracture region including the entire implant construct were obtained immediate postoperative to assess the construct and ensure stability. As regard postoperative ambulation and weight bearing, immediate weight bearing was started postoperatively as tolerated with walker or crutches with emphasis on heel strike and not toe-touch gait. Physiotherapy was started immediate postoperative in the form of hip abductor exercises in conjunction with proper balance and gait training till restoration of normal gait.

Protein and caloric nutrition, with vitamin D supplementation was started immediate postoperative. And on discharge, calcium (1,200 mg daily) and vitamin D (minimum of 1,000 IU daily) were prescribed and continued for about 3months postoperatively.

At second follow up 1 month postoperatively, a second look was taken on the wound, physiotherapy, ambulation and weight bearing instructions were learnt; and anteroposterior radiographs were taken.

At third follow up 2-3 months postoperatively, full weight bearing was started and anteroposterior radiographs were taken.

At forth follow up 4-6 months postoperatively, anteroposterior radiographs were taken. At the end of follow up the patient was assessed clinically and functional outcomes were evaluated using the Harris hip score.

\section{Statistical analysis}

Recorded data were analyzed using the statistical package for social sciences, version 20.0 (SPSS Inc., Chicago, Illinois, USA). Quantitative data were expressed as mean \pm standard deviation (SD). Qualitative data were expressed as frequency and percentage.

The following tests were done:

Independent-samples t-test of significance was used when comparing between two means.

Chi-square $\left(\mathrm{x}^{2}\right)$ test of significance was used in order to compare proportions between two qualitative parameters.

The confidence interval was set to $95 \%$ and the margin of error accepted was set to $5 \%$. The p-value was considered significant as the following:

Probability (P-value)

P-value $<0.05$ was considered significant.

P-value $<0.001$ was considered as highly significant.

$\mathrm{P}$-value $>0.05$ was considered insignificant.

\section{RESULTS}

This study had involved 20 patients with unstable trochanteric fractures who were prospectively followed up for 3-11 months with average of 7 months.

Table (1): Demographic data:

\begin{tabular}{|c|c|c|c|c|c|c|c|c|}
\hline No & $\begin{array}{l}\text { Age } \\
\text { years }\end{array}$ & Sex & Side & Mode of trauma & AO classification & complications & HHS & Comorbidities \\
\hline 1 & 72 & M & LT & Fall on his side & $31-\mathrm{A} 2.2$ & & 70.1 & HTN \\
\hline 2 & 75 & M & LT & Fall on his side & $31-\mathrm{A} 1.2$ & & 80.1 & HTN, DM \\
\hline 3 & 82 & $\mathrm{~F}$ & LT & Fall on her side & $31-\mathrm{A} 2.3$ & & 80.9 & \\
\hline 4 & 80 & $\mathrm{~F}$ & RT & Fall on her side & $31-\mathrm{A} 2.3$ & & 70.1 & HTN, DM \\
\hline 5 & 76 & $M$ & LT & Fall on his side & $31-\mathrm{A} 1.2$ & & 60.1 & HTN, IHD \\
\hline 6 & 75 & $\mathrm{~F}$ & LT & Fall on her side & $31-\mathrm{A} 2.3$ & & 60.1 & \\
\hline 7 & 85 & $\mathrm{~F}$ & LT & Fall on her side & $31-\mathrm{A} 2.3$ & & 44.3 & \\
\hline 8 & 80 & $\mathrm{~F}$ & RT & Direct Trauma & $31-\mathrm{A} 2.3$ & & 60.1 & \\
\hline 9 & 70 & $\mathrm{M}$ & LT & Fall on his side & 31-A1.1 & & 60.1 & DM \\
\hline 10 & 70 & $\mathrm{~F}$ & RT & Fall on her side & $31-\mathrm{A} 2.1$ & Infection & 42.1 & HTN \\
\hline 11 & 76 & $\mathrm{~F}$ & LT & Fall on her side & $31-\mathrm{A} 2.1$ & & 60.1 & \\
\hline 12 & 70 & $\mathrm{M}$ & LT & Fall on his side & $31-\mathrm{A} 2.3$ & & 60.1 & \\
\hline 13 & 83 & $\mathrm{~F}$ & LT & Fall on her side & $31-\mathrm{A} 2.2$ & & 55.5 & IHD \\
\hline 14 & 85 & $\mathrm{~F}$ & RT & Fall on her side & $31-\mathrm{A} 2.2$ & & 50.5 & HTN, DM \\
\hline 15 & 86 & $\mathrm{~F}$ & LT & Fall on her side & $31-\mathrm{A} 2.1$ & Mortality & 42.1 & IHD \\
\hline 16 & 75 & $M$ & RT & Fall on his side & $31-\mathrm{A} 2.3$ & & 47.2 & \\
\hline 17 & 75 & $\mathrm{~F}$ & LT & Fall on her side & $31-\mathrm{A} 2.2$ & Infection & 44.5 & DM \\
\hline 18 & 81 & M & LT & Fall on his side & $31-\mathrm{A} 2.2$ & & 60.1 & \\
\hline 19 & 73 & $\mathrm{~F}$ & RT & Fall on her side & $31-\mathrm{A} 2.1$ & & 55.3 & HTN \\
\hline 20 & 78 & $\mathrm{M}$ & LT & Fall on his side & $31-\mathrm{A} 2.3$ & & 74.5 & \\
\hline
\end{tabular}

As regard the distribution of patient sex, 8 patients were males (40\%) and 12 patients were females (60\%) 
Table (2): Age distribution:

\begin{tabular}{|c|c|c|c|}
\hline Age range & Mean \pm SD & Numbers & Percent \\
\hline $\mathbf{( 7 0 : 8 0 )}$ & $76.6 \pm 2.8$ & 12 & $60 \%$ \\
\hline$(81: \mathbf{9 0})$ & $84.2 \pm 1.6$ & 8 & $40 \%$ \\
\hline
\end{tabular}

As regard the distribution of patient age, the mean age was $77.45 \pm 3.5$ with range from $(70: 86)$ years old.

\section{Affected side:}

As regard the distribution of the affected side, the injuries were in the right side in 6 patients $(30 \%)$ and were in the left side in 14 patients $(70 \%)$

\section{Affected Side}

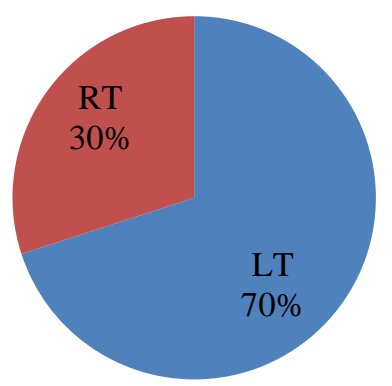

Figure (2): The distribution of the affected side.

\section{Mechanism of injury:}

As regard the distribution of mechanism of injury, the mode of trauma in all patients was due to simple fall on the side except in one patient whose mode of trauma was due to direct trauma to her side

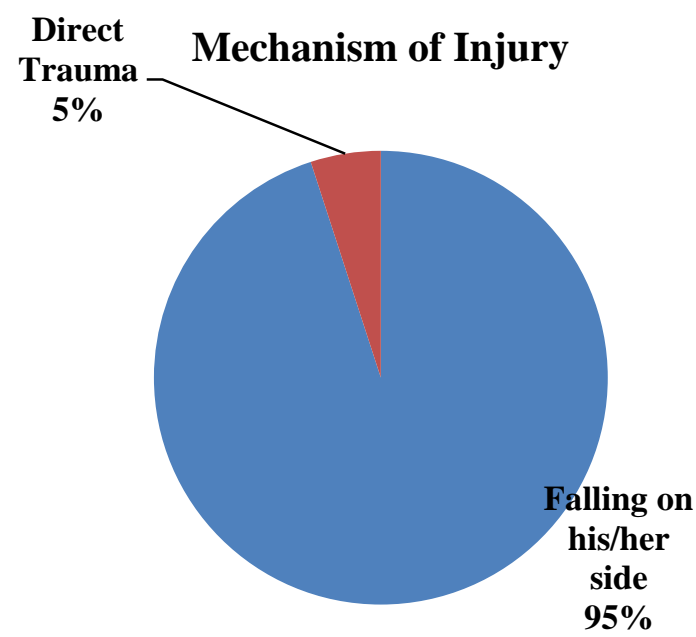

Figure (3): The distribution of mechanism of injury.

Table (3): postoperative complications:

\begin{tabular}{|c|c|c|}
\hline Complication & Number & Percent \\
\hline Infection & 2 & $10 \%$ \\
\hline Mortality (on table) & 1 & $5 \%$ \\
\hline No complications & 17 & $85 \%$ \\
\hline
\end{tabular}

\section{Case No 1}

\section{CASE PRESENTATIONS}

- Sex: male

- Age: 72 years old

- Side: Left side

- Mode of injury: fall on his side.

- Comorbidities: hypertensive and with past history of

- ipsilateral ischemic stroke 7 years ago.

- AO classification: $31-\mathrm{A} 2.2$

- Treatment Method: replacement by bipolar hemiarthroplasty.

\section{- Follow up:}

At first follow up 2 weeks postoperatively, the wound care was done with removal of sutures and immediate weight bearing was started.

At second follow up 1 month postoperatively, a second look was taken on the wound, physiotherapy, ambulation and weight bearing instructions were learnt; and anteroposterior radiographs was taken. At third follow up 6 months postoperatively anteroposterior radiograph was taken, functional outcome was assessed by Harris hip score.

- Harris hip score: 70.1 points (fair).

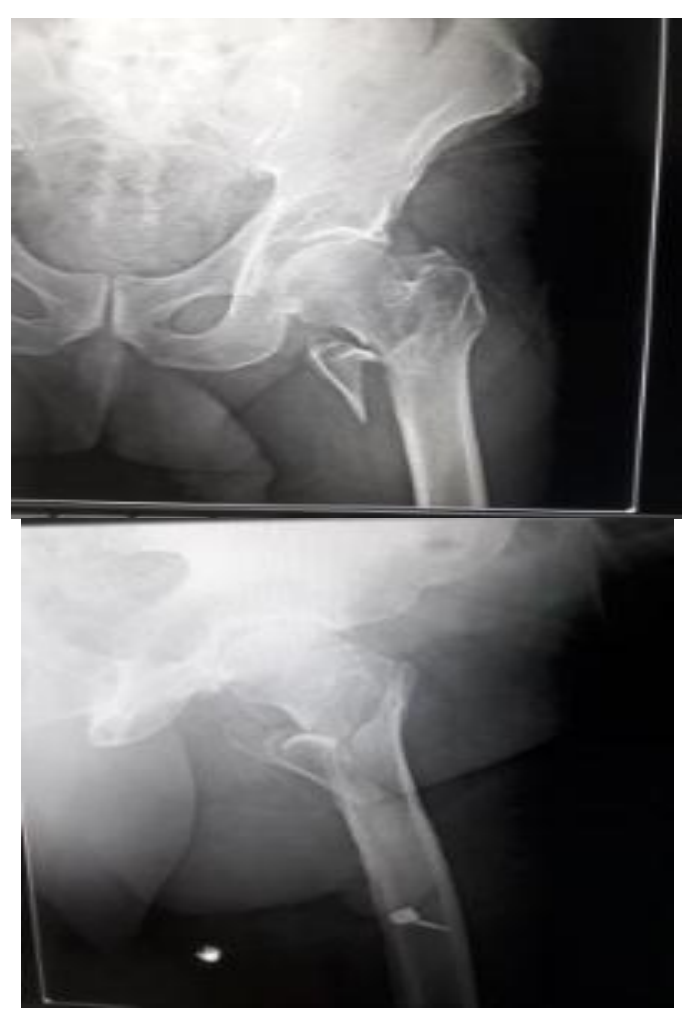

(A)

(B)

(B) Figure (4): Preoperative plain $x$-rays pelvis AP (A) and lateral frog views (B) showing left fracture intertrochanteric femur type 31-A2.2 according to AO classification. 


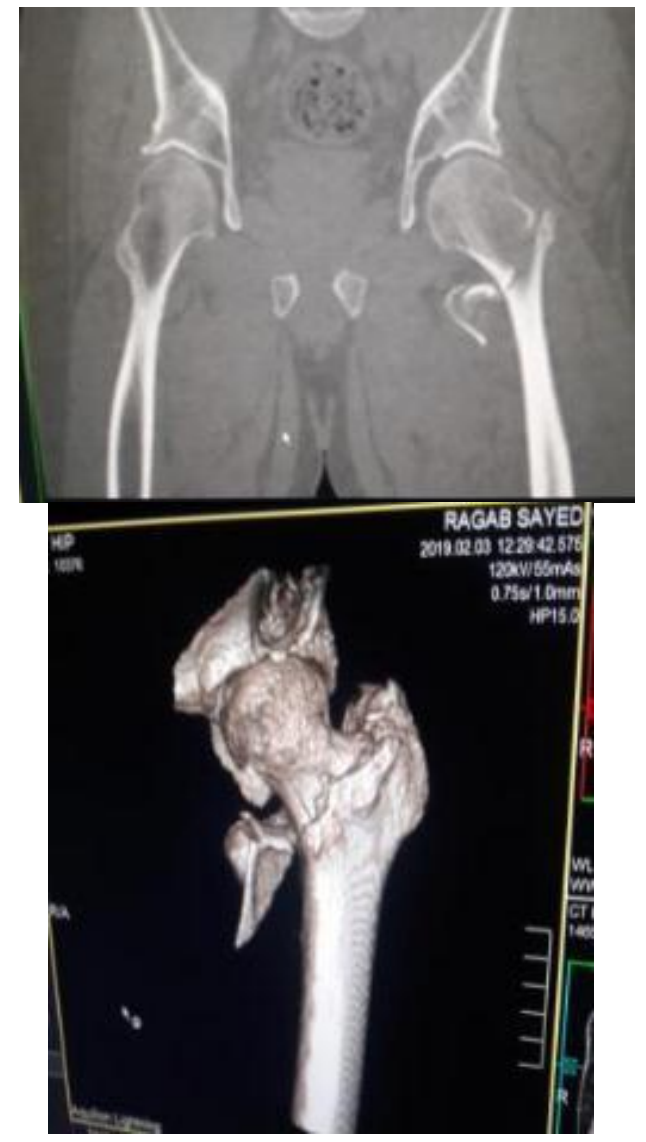

Figure (5): Preoperative CT scan of pelvis.

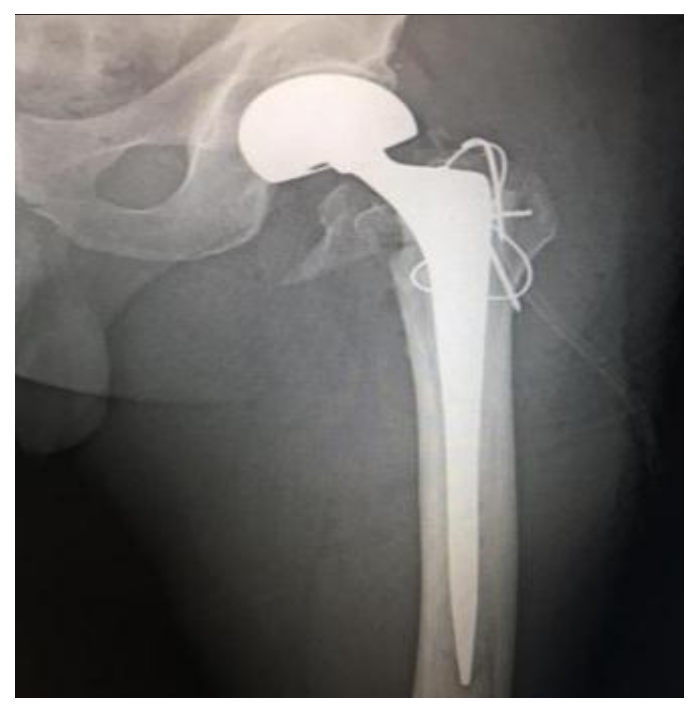

Figure (6): Immediate postoperative plain x-rays pelvis AP view showing

replacement of left fracture intertrochanteric femur by bipolar hemiarthroplasty.

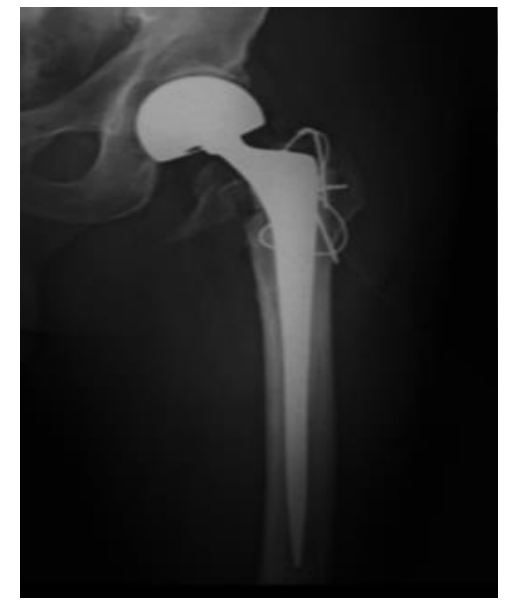

Figure (7): One month postoperative plain $x$-ray pelvis AP view of the same case.

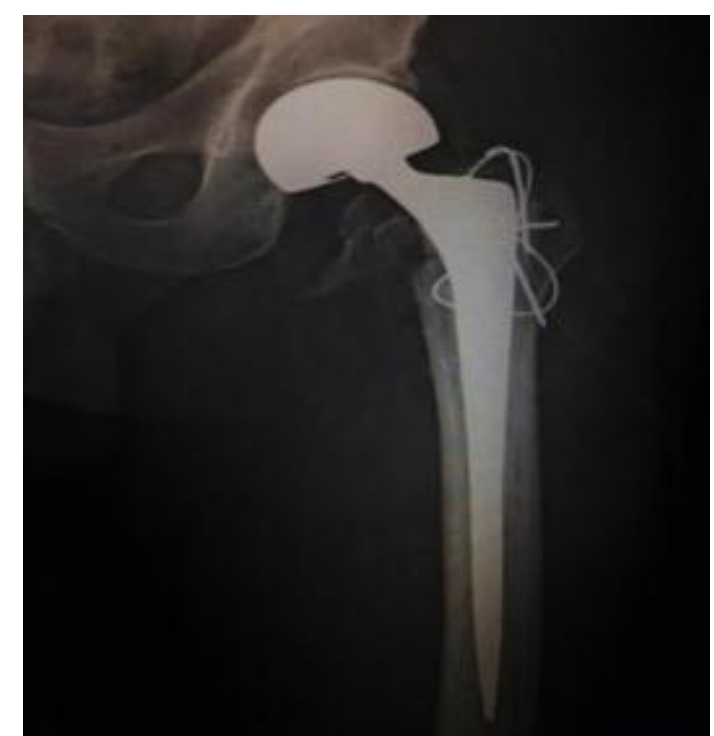

Figure (8): Six months postoperative plain $x$-ray pelvis AP view of the same case.

\section{CASE NO 2}

- Sex: male

- Age: 82 years old

- Side: Left side

- Mode of injury: fall on his side.

- Comorbidities: Hypertensive and diabetic.

- AO classification: 31-A1.2

- Treatment Method: Replacement with bipolar hemiarthroplasty.

- Follow up:

At first follow up 2 weeks postoperatively, the wound care was done with removal of sutures and immediate weight bearing was started.

At second follow up 1 month postoperatively, a second look was taken on the wound, physiotherapy, ambulation and weight bearing instructions were learnt; and anteroposterior radiographs were taken. At third follow up 4 months postoperatively anteroposterior 
radiographs were taken, functional outcome was assessed by Harris hip score.

- Harris hip score: 80.1 points (good)

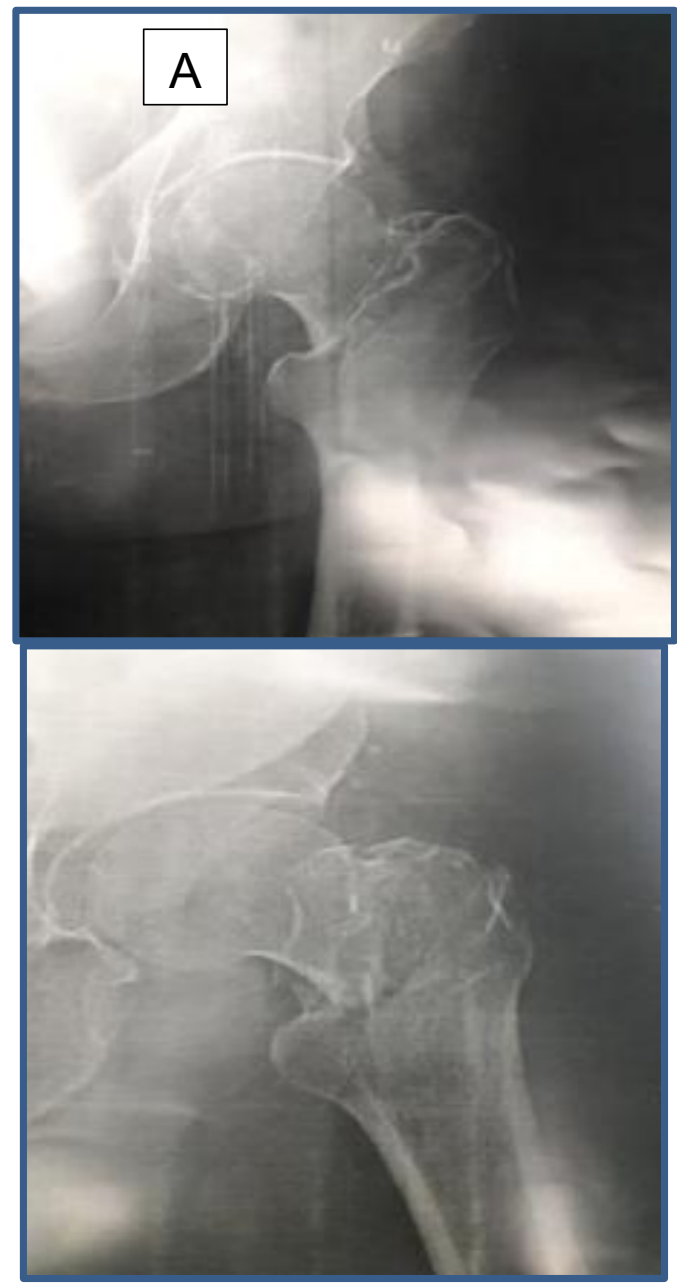

Figure (9): Preoperative plain $\mathrm{x}$-rays pelvis AP (A) and lateral frog views (B) showing left fracture intertrochanteric femur type 31-A1.2 according to AO classification.

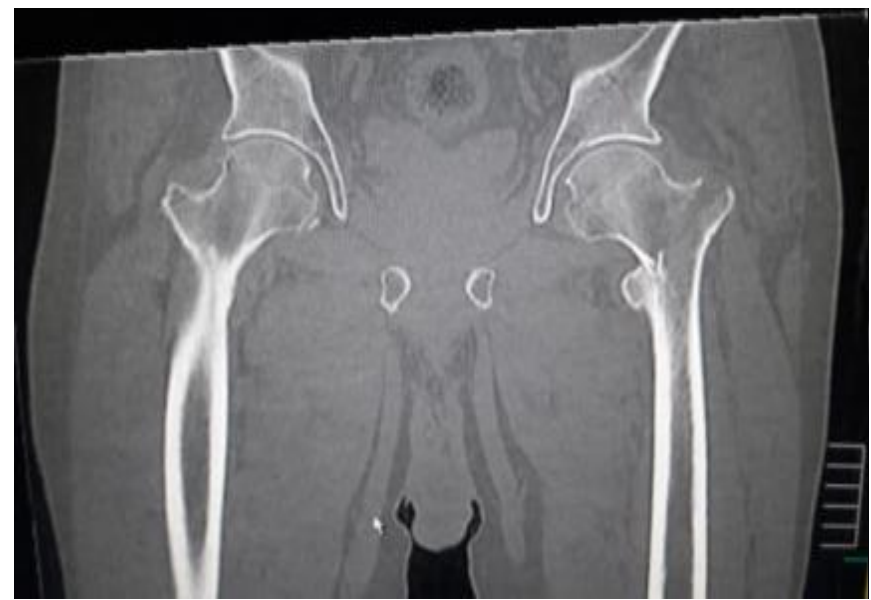

Figure (10): Preoperative CT scan of pelvis.

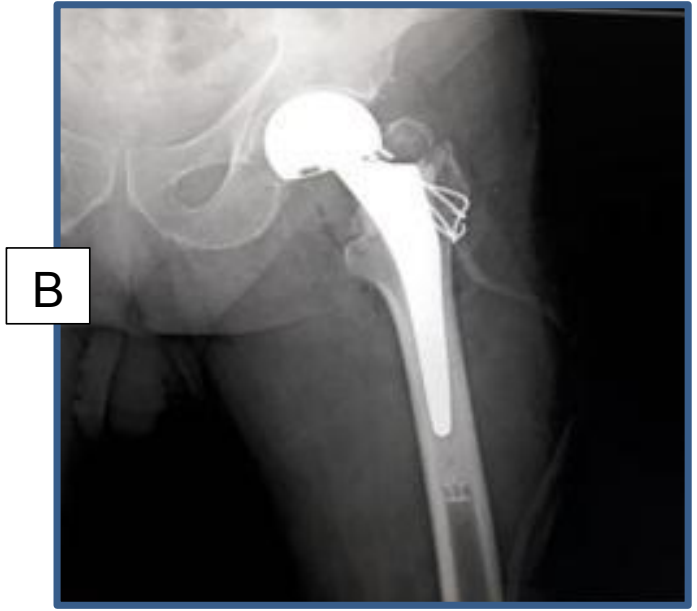

Figure (11): Immediate postoperative plain $\mathrm{x}$-rays pelvis AP view showing replacement of left fracture intertrochanteric femur by bipolar hemiarthroplasty.

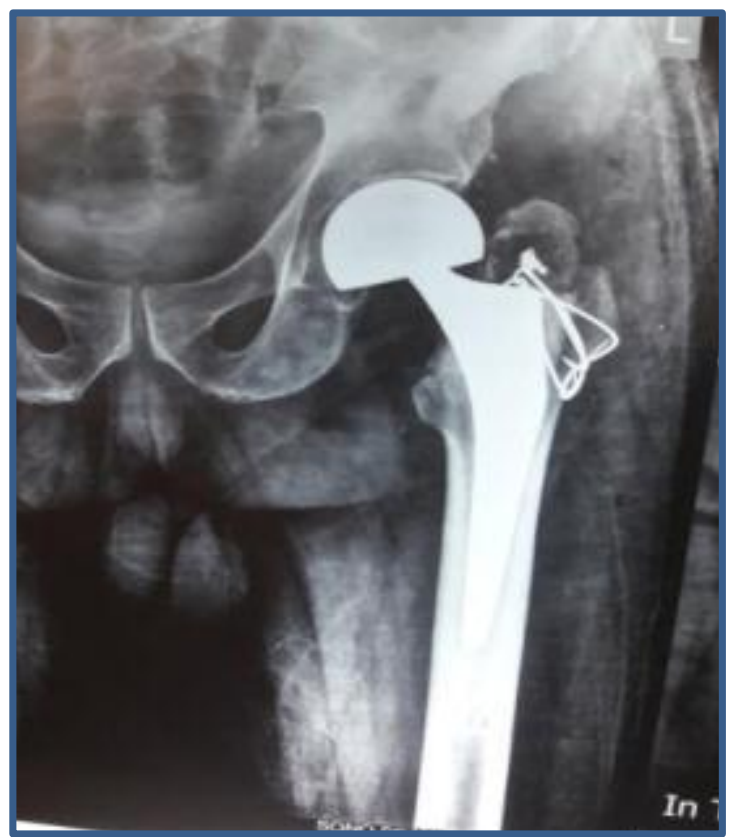

Figure (12): One month postoperative plain $x$-ray pelvis AP view of the same case.

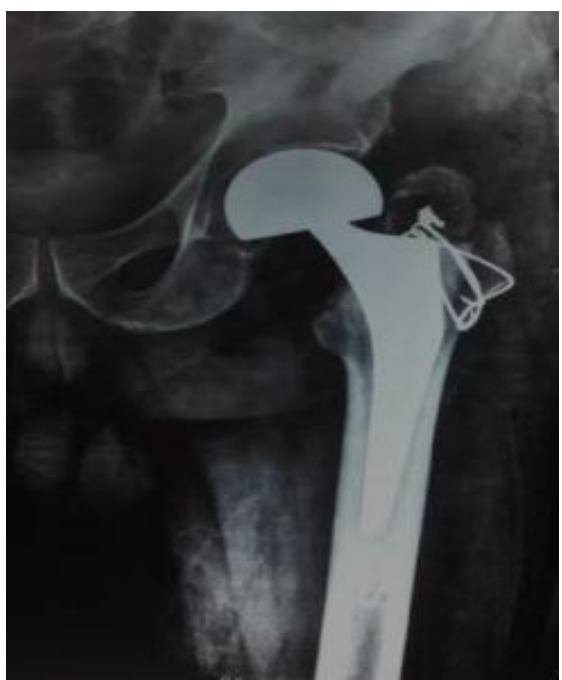

Figure (13): Six months postoperative plain x-ray pelvis AP view of the same case. 


\section{DISCUSSION}

Intertrochanteric fractures comprise about half of all hip fractures. They are common among elderly people that are more affected by osteoporosis and medical comorbidities as previous stroke with hemiparesis and Parkinson's disease. With the increasing age of the population and the longer survival of the aged, more unstable comminuted intertrochanteric fractures will be seen ${ }^{(8)}$.

Direct comparison of mortality rates is not feasible because of difficulty in matching critical factors such as age, gender, preinjury health status, social dependency, and fracture type. The in hospital mortality rate of $5 \%$ is comparable with $8 \%$ in Miller's series. It is higher than the $3 \%$ mortality rate reported by Kenzora et $\boldsymbol{a l} .{ }^{(9)}$ whose patients were on average almost 10 years younger.

The cumulative survival curve for the patients in this study has a tendency to be lower than that of Miller ${ }^{(10)}$, but within $95 \%$ confidence limits. One factor that contributed to this tendency of a lower survival rate was the higher mean age of the patients in this study.

Comparison with historic mortality rates is hampered not only by the inability to match patient characteristics but also by uncertainty as to how those mortality rates were calculated. Kenzora et al. ${ }^{(9)}$ gave a mortality rate at 1 year for intertrochanteric fractures as $15 \%$ on the basis that 33 of 219 patients died within the first year (average age, 75 years). This cannot be compared directly with the 1 -year cumulative mortality rate of $31.5 \%$ in the current patients because of differences in calculation of the mortality rate and a higher mean age of the patients (almost a decade older) (11).

The cumulative survival rate of the patients in this study at one year is $5 \%$. The $95 \%$ confidence limits for the cumulative survival rate at 1 year range. The mean operating time of 69 minutes (range, 35-130 minutes) is slightly shorter than the operative time using the Leinbach (80 minutes) or the BatemanLeinbach (75 minutes) prostheses but longer than the mean operating time of 41 minutes reported for hip pinning under fluoroscopy Harwin et al. ${ }^{(12)}$.

The time taken to position the patient on the fracture table and to reduce the fracture under biplane fluoroscopy is approximately 15 to 20 minutes. If this time is added to the operative time, then operating time of the current authors will be comparable with that using a standard compression hip screw. Haentjens $\boldsymbol{e t}$ al. (13) reported that in their institution the operative times for bipolar arthroplasty and internal fixation for intertrochanteric fractures are not significantly different.

Laskin et al. ${ }^{(14)}$ reported an average blood replacement of $700 \mathrm{~mL}$ for internal fixation of intertrochanteric fractures. This amount of whole blood replacement has approximately the same amount of red blood cells in 1.4 units of packed red blood cells. This is $25 \%$ lower than the mean blood use of 1.8 units of packed red blood cells for patients in the current study.

Nonunion and late fractures of the greater trochanter are not reported frequently for intertrochanteric fractures treated with sliding hip screws. It cannot be ascertained from this small series whether the painful nonunion of the greater trochanter in one patient and a traumatic fracture of the greater trochanter in another patient are peculiar to intertrochanteric fractures treated by hemiarthroplasties (15).

In the current study, data on the effect of internal fixation versus endoprosthesis on mortality rate are available only for femoral neck fractures. When adjusted for age, there is no significant difference in the mortality rates for patients treated with internal fixation or hemiarthroplasty. As the operating time and blood use in patients in the current series are only slightly greater than in the patients in whom the intertrochanteric fractures were treated with internal fixation, it is thought that the mortality and morbidity associated with using standard hemiarthroplasty for intertrochanteric fracture is not increased. Age, gender, pre-fracture health status, and social dependency before fracture are also important factors determining functional recovery after hip fractures. Direct comparison with other series is difficult. Eighty-five percent of patients (17 of the 20 patients who survived more than 6 months) retained walking ability after surgery.

This compares favorably with $76 \%$ reported by Laskin et al. (14) in their series of unstable intertrochanteric fractures and 78\% reported by Miller (10) in his patients with intertrochanteric and femoral neck fractures. Twenty percent of the patients in the current study (eight of 40 patients) recovered the walking ability they had before fracture.

This is lower than the series of Koval et al. (16), consisting of younger patients with mixed hip fractures where 42.6\% (192 of 451) regained their same walking ability as before fracture by 12-months follow-up. Another comparison can be made with the compression hip screw data from Laskin et al. ${ }^{(\mathbf{1 4})}$ who classified their patients at $\mathbf{6}$ months follow-up into five ambulatory categories ranging from walking without support to inability to walk.

Additional details of their classification were not given. The decrease in mobility and aids score in the patients in the current study was converted in a linear fashion to an equivalent decrease in ambulatory grade of Laskin et al. ${ }^{(14)}$. The comparison bar chart showed that these patients have a flatter distribution and the distribution is skewed slightly more to the left. The number of patients in this study is too small and the ambulatory measuring instruments are too crude to 
conclude that patients undergoing hemiarthroplasty do better ${ }^{(17)}$.

Given the few complications and a comparable functional recovery in this small series, the authors think that using cemented hemiarthroplasties with standard femoral stems is a reasonable alternative to a sliding screw device to treat intertrochanteric fractures (18).

The potential advantage of hemiarthroplasties for the treatment of intertrochanteric fractures warrants additional study in a larger number of patients to be compared with a matched control group treated with sliding screw devices. In addition to the walking ability and dependency on walking aids, independence in basic and instrumental activities need to be included in the larger outcome study 12 to ascertain the effectiveness of each type of surgical intervention. The more detailed functional evaluation may help identify a subgroup of patients who may benefit more from one form of surgical intervention than another ${ }^{(\mathbf{1 9})}$.

\section{CONCLUSION}

It could be concluded that the use of hemiarthroplasty is recommended for cases with old age, osteoporotic bone, medical comorbidities, preexisting ipsilateral symptomatic degenerative hip disease or patients with renal failure or pathological fracture with metastases.

\section{RECOMMENDATIONS}

Hopefully this study will stimulate other longer-term studies with larger number of patients to address the issue of whether there is any long-term benefit for patients. The issues of late complications and whether the reconstructions are durable enough for the longsurviving patients are yet to be addressed.

\section{REFERENCES}

1. Zuckerman JD (1996): Hip fractures. N Eng J Med., 334:1519.

2. Dahl E (1980): Mortality and life expectancy after hip fractures. Acta Ortho Scand., 51(1):163-70.

3. Stern Mark B, Goldstein Theodore B (1977): The Use of the Leinbach Prosthesis in Intertrochanteric Fractures of the Hip. Clinical Orthopaedics \& Related Research, $128: 325-331$.

4. Kaplan K, Miyamoto R, Levine BR, Egol KA, Zuckerman JD (2008): Surgical management of hip fractures: an evidence-based review of the literature. II: intertrochanteric fractures. J Am Acad Orthop Surg., 16: 665-73.

5. Nieves JW, Bilezikian JP, Lane JM, Einhorn TA, Wang Y, Steinbuch M (2010): Fragility: fractures of the hip and femur incidence and patient characteristics. Osteoporosis Int., 21(3):399-408.

6. Kubiak EN, Bong M, Park SS, Kummer F, Egol K, Koval KJ (2004): Intramedullary fixation of unstable intertrochanteric hip fractures: one or two lag screws. J Orthop Trauma, 18(1): 12-7.

7. Sancheti KH, Sancheti PK, Shyam AK, Joshi R, Patil K, Jain A (2010): Primary hemiarthroplasty for unstable osteoporotic intertrochanteric fractures in the elderly: A retrospective case series. Indian J Orthop., 44(4): 428-34.

8. Sevitt S, Thomson RG (1965): The distribution and anastomoses of arteries supplying the head and neck of the femur. J Bone Joint Surg Br., 47B:560-573.

9. Kenzora JE, McArthy RE, Lowell JD, Sledge CB (1984): Hip fracture mortality. Relation to age, treatment, pre operative illness, time of surgery and complications: Clin Orthop., 186: 45 -56.

10. Miller PR, Croce MA, Kilgo PD, Scott J, Fabian TC (2002): Acute respiratory distress syndrome in blunt trauma: identification of independent risk factors. Am Surg., 68(10):845-50.

11. Extermann M, Bonetti M, Sledge GW, O'Dwyer PJ (2004): Bonomi P, Benson AB 3rd., MAX2 - a convenient index toestimate the average per patient risk for chemotherapy toxic-ity; validation in ECOG trials. Eur J Cancer, 40:1193-1198.

12. Harwin SF, Stern RE, Kulick RG (1990): Primary Bateman Leinbach bipolar prosthetic replacement of the hip in the treatment of unstable intertrochanteric fractures in the elderly; Orthopaedics, 13: $1131-1136$.

13. Haentjens P, Casteleyn PP, Boeck H, Handelberg F, Opdecam P (1989): Treatment of unstable intertrochanteric and sub trochanteric fractures in elderly patients. Primary bipolar arthroplasty compared with internal fixation. JBJS., $71: 1214-1225$.

14. Laskin RS, Gruber MA, Zimmerman AJ (1979): Intertrochanteric fractures of the hip in the elderly: A retrospective analysis of 236 cases. Clin Orthop., 141: $188-195$

15. Parker MJ, Handoll HH (2010): Gamma and other cephalocondylic intramedullary nails versus extramedullary implants for extracapsular hip fractures in adults. Cochrane Database System Review, 8 (9):CD000093.

16. Koval KJ, Strauss E, Kummer F, Egol K (2007): The "ZEffect" Phenomenon Defined: A Laboratory Study. Journal of Orthopaedic Research, 25:1568- 1573.

17. Kaufer $H$ (1980): Mechanics of the treatment of hip Injuries. Clin Orthop Relat Res., 146.

18. Moroni A, Faldini C, Pegreffi F (2005): Osteoporotic pertrochanteric fractures can be successfully treated with external fixation. J Bone Joint Surg Am., 87(2):42-51.

19. Larsson $S$, Friberg $S$, Hansson $L$ (1990): Trochanteric fractures: Influence of reduction and implant position on impaction and complications. Clin Orthop Relat Res., 259:130 